\title{
The Holy Quran Revelation: Copper and it's Astonishing benefits for Humankind from a Chemical Perspective
}

\section{Aymen Labidi ${ }^{1}{ }^{*}, \dagger$}

${ }^{1}$ National Institute of Applied Sciences and Technology (INSAT), Centre Urbain Nord BP, Tunis, Cedex 1080, Tunisia, Department of Chemical Engineering

*aymenlabidi@insat.u-carthage.tn

${ }^{\dagger}$ Aeronautical Consultant for FTAA, Glider Former and Manager for Aerobotix INSAT

\section{Abstract}

One of the most important grants of God Almighty to mankind is iron and other metals such as Copper. The reality that there is mention of copper $(\mathrm{Cu})$ in the Holy Quran can be considered as a sign of it's big importance for the human life. The fact that copper was mentioned several times either under it's pure form or alloyed with iron might be a sign this metal is so useful for us and without it the human civilization would not progress.Verses "Ayat" of the Holy Quran are rich in meanings and words that need to be deeply managed and checked for understanding.The interpreters have begun to explain these meanings and words for thousands of years. However, as is well known, the Qur'an has lot of secrets that make it renewed and parallel to every age. In view of the modern scientific discoveries, many of the words of the Holy Quran have potential aspects of interpretation which are useful in understanding the purpose of these words. Therefore, most scholars have many scientific ideas and terms that explain the interpretation of the verses of the Quran and some of the Qur'anic terms from a scientific perspective that illustrates the scientific miracles in the Holy Quran. In this study we have addressed the Qur'anic word "Qitr" which was interpreted by the exponents as the dissolved copper in the field of Chemistry.

Key words: Copper; Copper Alloy ; Qitr ; The Holy Quran ; Chemistry

\section{Introduction}

After Praise be to Allah who, only through His guidance and assistance, made the pen poised to write and the tongue run to speak, and after peace and blessings be upon Prophet „Muhammad Seal of the messengers and the Imam of the Prophets, who was the most eloquent, lucid and articulate among the Prophets.

The scientific interpretation of the verses of the Quran and the meanings of words is a subject to be taken care of because of the its great impact in ones life and the society at large.

Therefore, we will address in this article the Quran term "Qitr" and "Nuhas" and we will show the great importance of Copper and it's Alloy.

\section{Copper}

Copper is the chemical element of atomic number 29, $\mathrm{Cu}$ symbol. The simple copper body is a metal.

Copper is an element of group 11 , period 4 , an element of the chalcophilic transition metal block.In the periodic table, copper is the same family as the silver and gold, because all have an orbital s occupied by a single electron on sub-layers $\mathrm{p}$ and completely filled, allowing the formation of metallic bonds. Naturally present in the earth's crust, copper (in low doses) is essential for the development of all life. It is mainly used by humans in the form of metal. Pure copper is one of the only metals colored with gold and osmium[1].

Copper is an element that is sometimes abundant in certain 
mining sites. The Clarke amounts to 55 to $70 \mathrm{~g}$ per tonne[2]. Copper is one of the few metals that exists natively under cubic lattice crystals (Figure 1).

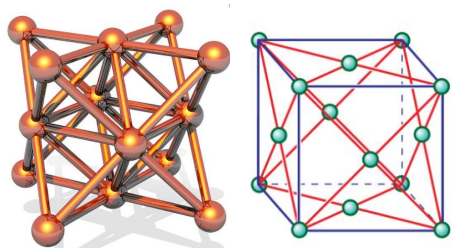

Figure 1. Face-Centred Cubic Structure of Copper

We also find Copper under alloys forms, which are metals that have copper as their principal component. They have high resistance against corrosion.

Studies were made of the mechanical and other properties of alloys over the entire composition range from pure copper to pure iron. Though the two-phase alloys have poor corrosion resistance unless protected, the composition in the vicinity of $65 \mathrm{pct} \mathrm{Cu}$ possesses an excellent combination of strength and electrical conductivity in the form of cold drawn wire. The alloys about 5 to 10 pct $\mathrm{Cu}$ have the highest strengths and are the most susceptible to improvement by age hardening treatment.

\section{Copper in the Holy Quran}

\section{The Cave: Verse 96}

"Bring me blocks of iron. At length, when he had filled up the space between the two steep mountain-cliffs, he said "blow", then when he had made it as fire, he said "bring me gitr to pour over it".

Figure 2

According to the interpretation of jami' Al-Bayaan fi Tafsir Al-Quran, Al-Tabari,

Allah the Almighty says that Dù Al-Qarnain told those who asked him "pour tar over it". Tar here means copper. This explanation was adopted equally by the scholars of the Holy Quran.

Some linguists in Basra, however, said that tar means "molten iron" and the following verse of poetry is cited to support the use and meaning of the term:

"A sword as white as salt, whose iron is crystal clear; Very sharp, of molten and spotless iron made."

Copper and its high copper alloys tend to passivate in humid air, forming an oxide layer (patina), which protects copper and its alloys from further corrosion processes.

From this Verse, we can clearly see how a chemical (Electrochemical) knowledge was applied, if Du Al-Qarnain made the wall from a pure Iron, se after a certain period of time, the iron rusts so that a loss of matter will occur, and here we can see the great importance of coating iron with copper so we can protect the iron from corrosion and we guarantee the wall persistence.

The is a method of coating iron with copper is to place in a crucible a quantity of chloride of copper, upon which is laid the iron to be coated, and over that a quantity of charcoal. The crucible is then submitted to a red heat and the chloride of copper fused, and a coating of copper deposited on the iron.

So we can conclude that 1400 years ago, the Quran revealed the secret of chemistry (Electrochemistry), the secret of Copper and how we can use it to protect some iron-based material from corrosion.

\section{Ar-Rahman: Verse 35}

"there will be sent against you both, smokeless flames of fire and copper, and you will not be able to defend yourselves" Figure 4

From this Verse, it's clear that human can not defend themselves against the smokeless flame of fire mixed with copper, But Why?

In Nuclear Physics and Chemistry, Copper is the unique element that, when is bombarded with high energy protons (Smokeless flame) emitted an antiparticle [3] which is a type of Standard Model particle of mass and spin equal to those of the corresponding particle, but of opposite quantum numbers which is an antiproton.

So we will have a neutralization between the particle (proton) and it's antiparticle (antiprtoton) and that's what we call the Annihilation.

When a proton encounters its antiparticle (and more generally, if any species of baryon encounters the corresponding antibaryon), the reaction is not as simple as electron-positron annihilation. Unlike an electron, a proton is a composite particle consisting of three "valence quarks" and an indeterminate number of "sea quarks" bound by gluons. Thus, when a proton encounters an antiproton, one of its quarks, usually a constituent valence quark, may annihilate with an antiquark (which more rarely could be a sea quark) to produce a gluon, after which the gluon together with the remaining quarks, antiquarks, and gluons will undergo a complex process of rearrangement (called hadronization or fragmentation) into a number of mesons, (mostly pions and kaons), which will share the total energy and momentum. The newly created mesons are unstable, and unless they encounter and interact with some other material, they will decay in a series of reactions that ultimately produce only photons, electrons, positrons, and neutrinos. This type of reaction will occur between any baryon (particle consisting of three quarks) and any antibaryon consisting of three antiquarks, one of which corresponds to a quark in the baryon[4].

\section{Conclusion}

Nothing that Allah has created is without purpose. Whether living or non-living, everything was made to benefit us, it is only now that science backs up everything that we have already been told about through our Holy Koran.

Day after day, the Holy Koran still reveal scientific facts that scientists have not yet discovered. Humankind must be connected to the Holy Koran and follow its guidelines since it is revealed by the Creator of the Universes.

\section{Supporting Information}




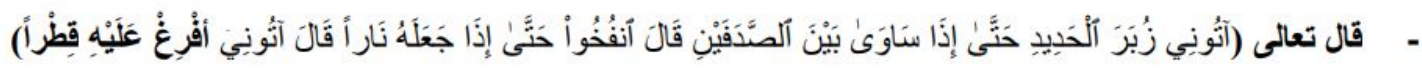 \\ سورة الكهف آية (7 (9)}

Figure 2. Chapter: Al-Kahf (The Cave); Verse (96)

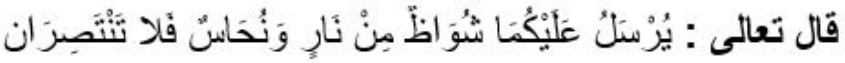

$$
\begin{aligned}
& \text { سوره الرحمان, اية } 35
\end{aligned}
$$

Figure 3. Chapter: Ar-Rahman ; Verse (35)

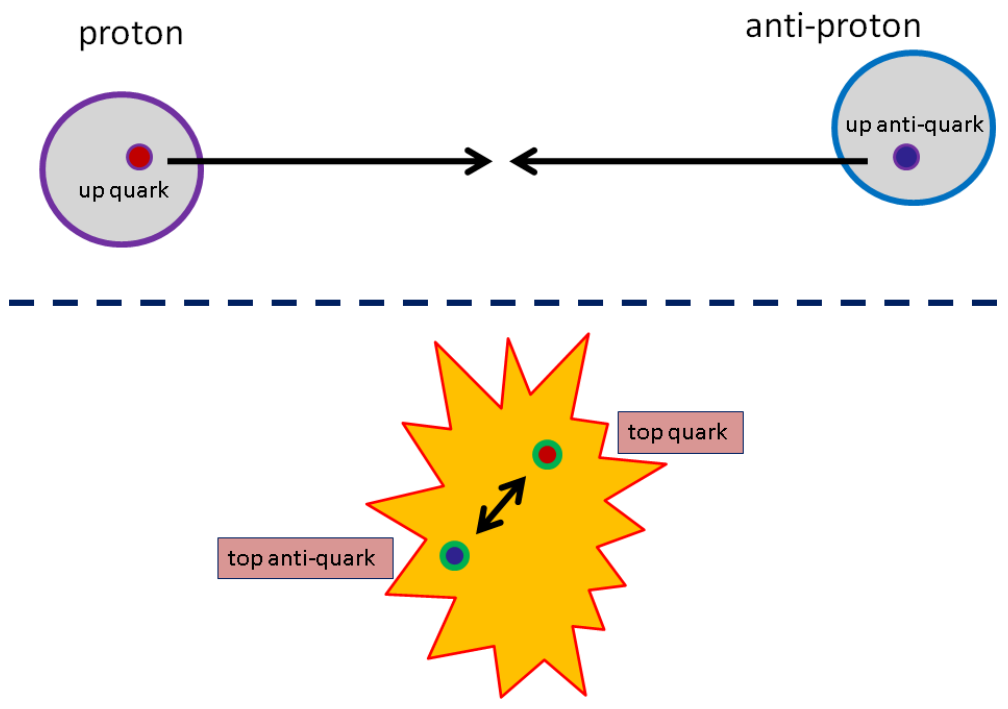

Figure 4. Proton and Antiproton reaction

\section{References}

1. Rezlescu N, Rezlescu E, Popa P, Craus M, Rezlescu L. Copper ions influence on the physical properties of a magnesiumzinc ferrite. Journal of Magnetism and Magnetic Materials 1998;182(1-2):199-206.

2. Milchman A, Rosenberg A. Michel Foucault and the genealogy of the holocaust. The European Legacy 1997;2(4):697699.

3. Borissov G. The Story of Antimatter: Matter's Vanished Twin. World Scientific; 2018.

4. Klempt E, Batty C, Richard JM. The antinucleon-nucleon interaction at low energy: Annihilation dynamics. Physics Reports 2005;413(4-5):197-317. 